\title{
MENSTRUATION: AN ABLEIST NARRATIVE
}

\section{PRIANKA NAIR*}

The stories that we tell, or don't tell, about bodies matter.

Libresse's 2016 advertisement for menstrual products features a dancer peeling off her ballet slipper to reveal bloodied mangled toes, a cyclist bleeding from a scrape on her leg, a soccer player bleeding from the bridge of her nose. The slogan-powerful and unvarnished - is "No Blood Should Hold Us Back." It is an empowering message that reinforces the ubiquity of menstruation. The ad avoids anodyne representations of blue liquid poured from a laboratory beaker onto a sterile menstrual pad. It prides itself on showing blood on female bodies. This is a feminist message that challenges the cultural script of stigma and secrecy around menstruation.

It is worth noting, however, that Libresse's advertisement does not include a single individual with a disability. It presents a view of how the menstruating body should occupy the world - strong, capable, independent, autonomous - without accommodation or assistive aids. Narratives like this, although ostensibly rewriting the story of the menstruating body, erase the experience of menstruators who require assistance from caregivers to change their pads or have decisions about their menstruation left to legal guardians, doctors, and courts. This story is not limited to this particular advertisement. Menstruators with disabilities report feeling like they have to comply with the norms of able-bodied menstruators, giving rise to different forms of discrimination and marginalization. ${ }^{1}$ The narrative Libresse promotes is feminist, but it is also fundamentally ableist.

The dominant narrative of disability and menstruation is frequently told in courts. Individuals with disabilities are frequently subject to oppression due to ableism-a system of beliefs that "not only signals disability as a form of difference but constructs it

\footnotetext{
* Assistant Professor of Clinical Law, Co-Director of the Disability and Civil Rights Clinic, Brooklyn Law School.

${ }^{1}$ Linda Steele \& Beth Goldblatt, The Human Rights of Women and Girls with Disabilities: Sterilization and Other Coercive Responses to Menstruation, in The Palgrave Handbook of Critical Menstruation Studies 77, 79 (Chris Bobel, Inga T. Winkle, Breanne Fahs, Katie Ann Hasson, Elizabeth Arveda Kissling, Tomi-Ann Roberts eds., 2020).
} 
as inferior." ${ }^{2}$ This ableism seeps into the jurisprudence surrounding menstruation. Curial discussion around menstruation management occurs in the context of petitions to sterilize the individual — the most drastic and irrevocable form of menstrual suppression. The very framing of the enquiry marginalizes the experience of menstruators with disabilities, confirming their status as bodies that need management and medical intervention. While courts are generally protective of the fundamental and constitutionally protected rights of individuals with disabilities to procreate, they effectively shift the decision-making around sterilization and menstrual management from the individual into the hands of medical professionals. ${ }^{3}$

This essay outlines how the focus on able-bodied menstruators in the development of social narratives about menstruation erases the experiences and the discrimination experienced by menstruators with disabilities. Many menstruators with disabilities experience shame around menstruation, embarrassed about the "burden" of their menstrual experiences on their caregivers and concerned about breaching menstrual etiquette around hygiene. Narratives about menstruation are incomplete without considering these experiences. Introducing a disability perspective also permits us to interrogate why popular depictions of the menstruating body are inadequate, how they continue to reinforce and romanticize values like independence and productivity, and validate structures that grant power and privilege to those values. Finally, the essay introduces ideas like supported decision-making and dismodernism that center the experiences of individuals with disabilities. This shift in focus has the potential to transform menstrual activism by introducing into the conversation more nuanced values of reciprocity, interdependence, and empathy.

\footnotetext{
${ }^{2}$ Liat Ben-Moshe, Decarcerating Disability: Deinstitutionalization and Prison Abolition 16 (2020).

${ }^{3}$ See e.g., Matter of Guardianship of Hayes, 608 P. 2d 635, 640 (1980) (stating that sterilization may be justified where there is "substantial medical evidence"); P.S. by Harbin v. W.S., 452 N.E.2d 969, 972 (1983) (finding that there was ample evidence that P.S., a child with autism, should be sterilized over her objections based on evidence from her neurosurgeon that it would be "very dangerous for P.S. to menstruate" as she could become "extremely excited when she sees her blood," would hurt herself during these excitatory episodes and would be unable to care for herself during her menstrual cycles."); but cf. Matter of Guardianship of Eberhardy, 307 N.W.2d 881, 895 (1981) (advocating for judicial restraint in granting petitions to sterilize individuals with disabilities even where the court is provided with testimony from expert medical witnesses because "it would appear that the exercise of judicial discretion unguided by well thoughtout policy determinations reflecting the interest of society, as well as of the person to be sterilized, are hazardous indeed.")
} 


\section{The Subordination of Disabled Voices}

Menstrual activism is premised on notion of taking back control over the meaning and experience of menstruation. An outgrowth of mid-to-late twentieth century feminist women's health activism, the movement recognizes that menstruators, particularly women, rarely get to define the meaning of their bodily processes. ${ }^{4}$ Rather, this has been left to physicians, corporations, and pharmaceutical companies. ${ }^{5}$ The goals of the menstrual activism movement are to challenge the representation of menstruation, push past stigma to have meaningful conversations about body literacy, create safe and effective products to manage menstruation, and challenge the manipulation and suppression of menstruation. ${ }^{6}$

However, the menstrual activism movement has been criticized as being primarily white, heteronormative, and able-bodied. ${ }^{7}$ It takes privilege to embrace notions of health care and consumerism that radically depart from the mainstream. ${ }^{8}$ As a result, the movement has not been especially inclusive of menstruating bodies with disabilities. Other excluded populations include women of color. ${ }^{9}$ Bloggers like crippledscholar have noted that "there is very little written about disability and menstruation generally and what little there is [] most often not written by disabled people." ${ }^{10}$ As a result, she writes, "a lot of it is about control and often menstrual cessation in order to make the menstruating person more convenient for a care giver." ${ }^{11}$ Activist, author, and podcaster

\footnotetext{
${ }^{4}$ Chris Bobel, New Blood: Third-wave Feminism and the Politics of Menstruation 27 (2010).

${ }^{5} I d$

${ }^{6} I d$. at 8 .

${ }^{7}$ Id. at 135 .

${ }^{8} I d$.

${ }^{9}$ BoBeL, supra note 4, at 11 (noting that the absence of women of color is a feature of the menstrual activism movement but noting that a disproportionate number of queer activists populate the movement).

${ }^{10}$ Let's Talk About Disability, Periods, and Alternative Menstrual Products, CRIPPLEDSCHOLAR (July 8, 2016), https://crippledscholar.com/2016/07/08/lets-talk-about-disability-periods-and-alternative-menstrualproducts/ [https://perma.cc/GG52-2GZ2].

${ }^{11} I d$.
} 
Alice Wong notes that although menstruation is a natural process, "we get medicalized, the whole process." 12

Certainly, the principles central to menstruation activism, including autonomy of one's own body and the right to make one's own medical decisions, ring hollow in light of legal regimes, like guardianship, that routinely deprive individuals with disabilities of this autonomy. As noted above, decisions about the bodies of individuals with disabilities are frequently outsourced to third parties, particularly if they are deemed to lack mental capacity.$^{13}$ While it would be a criminal offense and civil legal wrong to touch another's body without consent, the law denies this protection to individuals who are assumed to lack mental capacity, allowing judges, parents, and guardians to make decisions about the legality of sterilization and other means of menstrual suppression. ${ }^{14}$ In these circumstances, these interventions do not constitute unlawful contact.

Further, while menstrual activists resist the pathologizing of the menstruating body, emphasizing the importance of self-care and the movement away from the medical establishment as the source of knowledge over menstruating bodies,$^{15}$ the bodies of menstruators with disabilities continue to be viewed through a medical lens. The medical model of disability primarily sees disability as an individual deficit that demands medical intervention over and above the objections of the individual.

Within the context of menstruation, the perception of individuals with disabilities as being unable to manage menstruation has historically resulted in coercive interventions by parents, caregivers, medical professionals and courts. ${ }^{16}$ For instance, in Brode $v$. Brode, the parents of an eleven-year-old girl diagnosed with "hyperactivity, cerebral palsy and the tendency to experience seizures," sought judicial permission to perform an hysterectomy upon her. ${ }^{17}$ Not only did the court hold that appellate counsel had failed to

\footnotetext{
${ }^{12}$ Disability Visibility Podcast, Disabled Inventors (Aug. 13, 2018), [https://perma.cc/Z7RM-DZCK].

${ }^{13}$ Steele \& Goldblatt, supra note 1, at 82-83.

${ }^{14} \mathrm{Id}$. at 82 .

${ }^{15}$ BoBel, supra note 4, at 133.

${ }^{16}$ While not all individuals with disabilities require direct assistance from a caregiver to manage their daily living activities, this Article focuses on those cases, as they expose the way in which third parties can become intimately involved in the lives and bodily decision of individuals with disabilities.
}

${ }^{17}$ Brode v. Brode, 278 S.C. 457,459 (1982). 
"assert that Deanna's real interests will be served by continued menstruation,"18 but it also criticized the lengthy treatment in counsel's brief about the history of eugenics and sterilization of individuals with disabilities. ${ }^{19}$ In this manner, the court refused to consider the social and cultural practices that have permitted discrimination against individuals with disabilities in the curtailment of their reproductive rights. In the Matter of Guardianship of $A . W$., the parents of a woman with a disability petitioned the court because of their concern that "A.W. did not understand her physical maturation, including menstruation," 20 causing her "a considerable degree of fright, fear and a general feeling of unrest." 21 While the court noted that the "welfare of society or the convenience or peace of mind of parents or guardians" were not relevant to the assessment of whether sterilization was required or appropriate, the court also made it clear that the wishes of the person would not be conclusive and that the person's presence in the court room was not required..$^{22}$ Rather, the court indicated that sterilization would be permitted if it was "medically essential," placing the decision squarely in the hands of medical experts. ${ }^{23}$

Admittedly, the aforementioned cases are old - the decision in Brode, for instance, was written in 1982 - but they express how courts continue to marginalize the voices of menstruators with disabilities. Furthermore, sterilization continues to be a legal option in the U.S., as recognized in 2001 by the Eighth Circuit Court of Appeals. ${ }^{24}$ And there is evidence that families continue to turn to sterilization as a way of managing the menstrual needs of individuals with disabilities. In 2008, the mother of a twenty-two-year-old woman with an intellectual disability sought involuntary sterilization of her daughter, Carmen, on the basis that she had a history of kidney infections arising from her poor hygienic care for her menstrual periods. ${ }^{25}$ The OB/GYN accepted the mother's report and agreed to perform a partial hysterectomy without examining Carmen. The matter was

\footnotetext{
${ }^{18} I d$. at 460.

${ }^{19}$ Id. at $460-61$.

${ }^{20}$ In re A.W., 637 P.2d 366, 367 (Colo. 1981).

${ }^{21} I d$. at 368 .

${ }^{22} I d$. at $375-76$.

${ }^{23} \mathrm{Id}$.

${ }^{24}$ Vaughn v. Ruoff, 253 F.3d 1124 (8th Cir. 2001).

${ }^{25}$ David Carlson et al., Devaluing People with Disabilities: Medical Procedures that Violate CIVIL Rights 21 (National Disability Rights Network, 2012).
} 
brought to guardianship court, not by the family, but by the North Dakota Protection and Advocacy Project. The Project demonstrated that Carmen did not have abnormally painful menses or urinary tract infections, received assistance to manage her menses, and did not consent to sterilization.

Other decisions regarding menstrual management may be decided without judicial intervention, through conversations between doctors, the guardians, and the parents of the individual with the disability. While the American Pediatric Association recommends that the individual be included in this conversation, it is difficult to gauge how frequently this happens, or whether the individual is included in a meaningful way. ${ }^{26}$ Menstruation is often linked to the developing sexuality of the individual, and society has tended to infantilize people with disabilities, downplaying their sexual desires and the need for sexual education. In this context, it is probable that discussions about menstruation are charged with bias toward menstrual suppression.

It is imperative for menstrual activism to incorporate and amplify the voices of menstruators with disabilities. The marginalization and complete subjugation of these voices to those of caregivers, courts, or medical professionals has real adverse consequences. As Wilbur et al. note, "the societal beliefs and taboos around menstruation and disability means the issue is shrouded in silence, and that it lacks attention and resources." ${ }^{27}$ For many menstruating individuals with disabilities, menstruation is seen as a luxury, linked to ableist ideas of sexuality and reproduction. ${ }^{28}$ Others experience shame around menstruation etiquette, embarrassed by the "burden" that menstruation places on caregivers or support staff. ${ }^{29}$ Undoubtedly, the lack of representation of their experiences in dominant narratives about disability has further isolated and silenced them.

Conversely, when we incorporate a disability perspective, we get a richer and more nuanced understanding of the menstrual body, including the problems with the dominant narrative of the fit and able-bodied menstruating body.

\footnotetext{
${ }^{26}$ Elizabeth H. Quint \& Rebecca F. O’Brien, Menstrual Management for Adolescents with Disabilities, 138 Am. Pediatric Ass'N 2 (2016).

${ }^{27}$ Jane Wilbur et al., Systematic Review of Menstrual Hygiene Management Requirements, its Barriers and Strategies for Disabled People 14(2) Plos ONE, Feb. 2019, at 13, https://journals.plos.org/plosone/article?id=10.1371/journal.pone.0210974 [https://perma.cc/5VW4-TGJA].

${ }^{28}$ Steele \& Goldblatt, supra note 1 , at 79-80.

${ }^{29} I d$. at 81 .
} 


\section{Centering Disability in Menstruation Narratives}

There is a tendency to think of disability issues, including disability discrimination, as niche and unrelated to the broader experiences of the population. This is a myopic view that fails to consider the complex identities of individuals with disabilities and the multiple manifestations of menstruation discrimination. Often, the rationale for sterilization or menstrual suppression derives from the anxiety that the individual would not be able to cope with the changes of the maturing body. A drastic example of this is the case of Ashley X, a six-year-old child with static encephalopathy, whose uterus and breast buds were removed to prevent her from menstruating or developing breasts, permanently preventing the onset of puberty. Against a backdrop of broad condemnation from the disability rights community, Ashley's parents saw the operation as a success, telling CNN in 2008 that "Ashley did not grow in height or weight in the last year, she will always be flat-chested and she will never suffer any menstrual pain, cramps or bleeding. ${ }^{, 30}$ While this is a story about disability discrimination, it is also about gender discrimination. ${ }^{31}$ As Alison Kafer points out, the growth attenuation treatment applied to Ashley $\mathrm{X}$ was "a cure for adult womanhood as much as adult disability." 32

What if, rather than marginalizing the experiences of individuals with disabilities, we were to place them at the center of the menstrual experience? Jane Hartman Adamé, the creator of the Keela menstrual cup, observes that:

If we allow the voices of our most challenged users to be heard, solving a huge problem for some can mean solving an inconvenience for everyone else. Inevitably, inclusive design benefits all of us. When we factor in the

\footnotetext{
${ }^{30}$ Alison Kafer, At the Same Time, Out of Time: Ashley X, in The New Disability History 287 (Paul K. Longmore \& Lauri Umansky eds., 2001).

${ }^{31}$ While the focus of this Article is primarily on the experience of women with disabilities, men with disabilities are often subject to sterilization because of discomfort and concerns from family members, guardians and caregivers about the ability of these individuals to handle their maturing bodies and manage their sexual needs. See, e.g., In re Guardianship of Kennedy, 845 N.W.2d 707, 709 (Iowa 2014) (concerning a case where a guardian forced her son to undergo a vasectomy when she became concerned that he was having sex with a coworker).

${ }^{32} I d$. at 290.
} 
people at the extreme ends of use, we end up making something that is easier for the folks in the middle as well. ${ }^{33}$

Applying a disability lens to the narratives around menstruation allows us to question presumptions underlying the representation of the menstrual body. Feminist theory interrogates how race, class, gender, ethnicity, and sexuality mutually construct and contradict one another. Including a disability/ability category of analysis enriches this conversation. As Rosemarie Garland-Thomson puts it: "Integrating disability clarifies how this aggregate of systems operates together, yet distinctly, to support an imaginary norm and structure the relations that grant power, privilege and status to that norm." ${ }^{34}$

By tacitly adopting liberal ideas of autonomy and independence, values that "fuel the broader impulse toward women's empowerment," Garland-Thomson writes that "feminist practice often leaves no space for the needs and accommodations that disabled women's bodies require. ${ }^{\prime 35}$ However, if we look more deeply at these values, it is possible to see how they justify and support inequality. Ideas like productivity and autonomy can be linked to the way work has evolved under capitalism. Marta Russell and Jean Stewart note that "industrial capitalism commodified the human body . . . creating a class of "disabled" whose bodies did not conform to the standard worker physique and whose labor power was effectively ignored." ${ }^{36}$ It became justifiable to remove and segregate disabled bodies in workhouses and institutions simply because they were not as productive. Discrimination on the basis of disability has also been justified by the belief that disabled bodies are dependent bodies. However, "independence" is a patriarchal value, based on the notion that "adequate adults are strong and fit," physically and emotionally, often contrasted against a feminine ethic of care. ${ }^{37}$

\footnotetext{
${ }^{33}$ Jane Hartman Adamé, I Designed a Menstrual Cup That's Easier for Disabled People to Use, TeEn Vogue (Dec. 30, 2017), https://www.teenvogue.com/story/menstrual-cups-for-disabled-people [https://perma.cc/NA8D-67FM].

${ }^{34}$ Rosemarie Garland-Thomson, Integrating Disability, Transforming Feminist Theory, 14 N.W.S.A. J. 1, 4 (2002).

${ }^{35}$ Rosemarie Garland-Thomson, Ctr. For Women Pol'y Stud., Re-Shaping, Re-Thinking, Re-Defining: FEMINIST DisABILITY StUDiEs 6 (Sept. 2001), https://www.womenenabled.org/pdfs/GarlandThomson,Rosemarie,RedefiningFeministDisabilitiesStudiesCWPR2001.pdf [https://perma.cc/896Q-LUDV].

${ }^{36}$ Marta Russell \& Jean Stewart, Disablement, Prison and Historical Segregation, MonThly Rev. (Jul. 1, 2001), https://monthlyreview.org/2001/07/01/disablement-prison-and-historical-segregation/ [https://perma.cc/AP2Y-JQEB].

${ }^{37}$ Susan Wendell, Toward a Feminist Theory of Disability, 4 Hypatia 104, 118 (1989).
} 
"What is universal in life," writes Lennard J. Davis, "if there are universals, is the experience of the limitations of the body." 38 Davis proposes a "dismodernist" view of the body, that recognizes that all bodes are disabled and require aids to function: "[r]ather than the idea of the complete, independent subject, endowed with rights (which are in actuality conferred by privilege), the dismodernist subject sees that metanarratives are only 'socially created' and accepts them as that, gaining help and relying on legislation, law and technology." "39 In this world, "dependence is reality, and independence grandiose thinking." 40

Practically, a dismodernist perspective allows for a more nuanced understanding of independence and autonomy. It shifts the focus from narratives about the body to the social norms and structures that result in the oppression of the body. An example of this dismodernist approach can be found in supported decision-making models. While guardianship is premised on the notion that the individual is incapable of making independent decisions, thereby requiring a surrogate decision maker to stand in their shoes to make those decisions, supported decision-making dismantles the falsehood that people are islands. Rather than supplanting the decisions of the individual, supported decision making involves the creation of a plan that allows the individual to retain their decision-making capacity, while selecting trusted advisors, such as friends, family members, or professionals, to understand, consider, and communicate decisions about health care and financial or property management. Supported decision-making values community and interdependence over the false narrative of independence.

Applying a supported decision-making model to menstruation facilitates the creation of a community around menstruators with disabilities. Rather than stripping away autonomy or penalizing individuals with disabilities because of the support they may require during menstruation, we can recognize that all menstruators require assistance and support. Supported decision-making, with respect to menstruation, could explicitly address the individual's menstruation management needs and the support system that they can rely upon to make decisions about reproduction or menstrual suppression. Supported decision-making provides a framework that enables individuals with disabilities to better locate and communicate pain associated with menstruation, and direct research to menstrual product preference and effectiveness for people with different impairments. A dismodernist view of menstruation incorporates the stories of

\footnotetext{
${ }^{38}$ LeNNARD J. DAVIS, BENDING OVER BACKWARDS 32 (2002).

${ }^{39} \mathrm{Id}$. at 30 .

${ }^{40} I d$. at 31 .
} 
those for whom menstruation is difficult, because of oppressive social systems rather than limitations of the body itself. This story includes poor women, trans or gender nonconforming individuals who menstruate, and individuals with disabilities.

$* * *$

While searching for stories about menstruation, I found a video featuring a girl, Jill, with Down's Syndrome. Filmed in 1967, the images are grainy and the video lacks dramatic music, but the story is clear. Jill asks her mother questions about menstruation. Jill's sister takes her to the bathroom to show her what the blood looks like when it is on a pad. This video was by no means unproblematic. While it was one of the few sources of information on menstruation management that I found that featuring a person with a disability as the central character, it contextualized menstruation as something that only women did, thereby excluding the experiences of trans and gender non-conforming people altogether. However, the narrative does promote the values of interdependence and community, dignifying and demystifying the menstrual experience for people with disabilities. To ensure menstrual equality, it is imperative that we continue to explore empowering narratives that celebrate the experiences of all menstruating bodies. 